
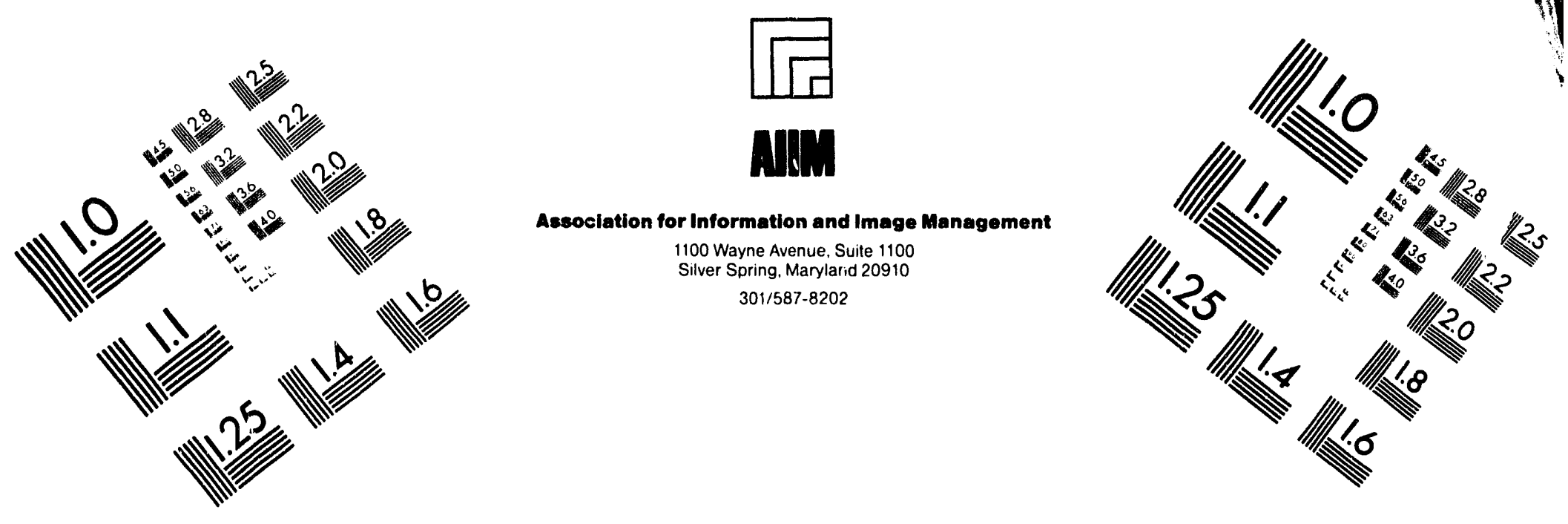

Centimeter

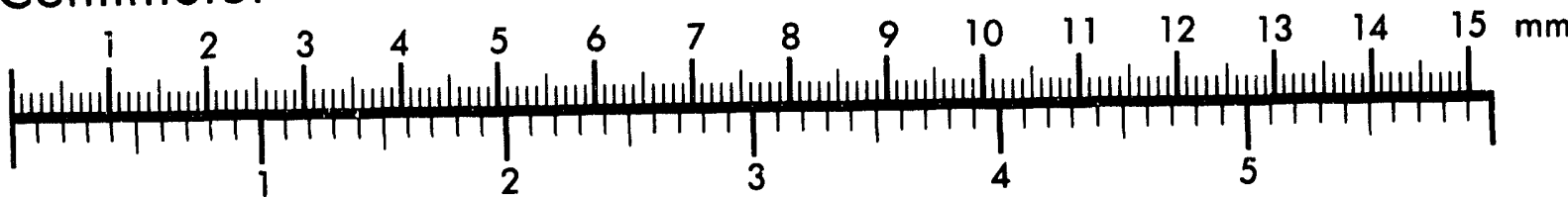
Inches
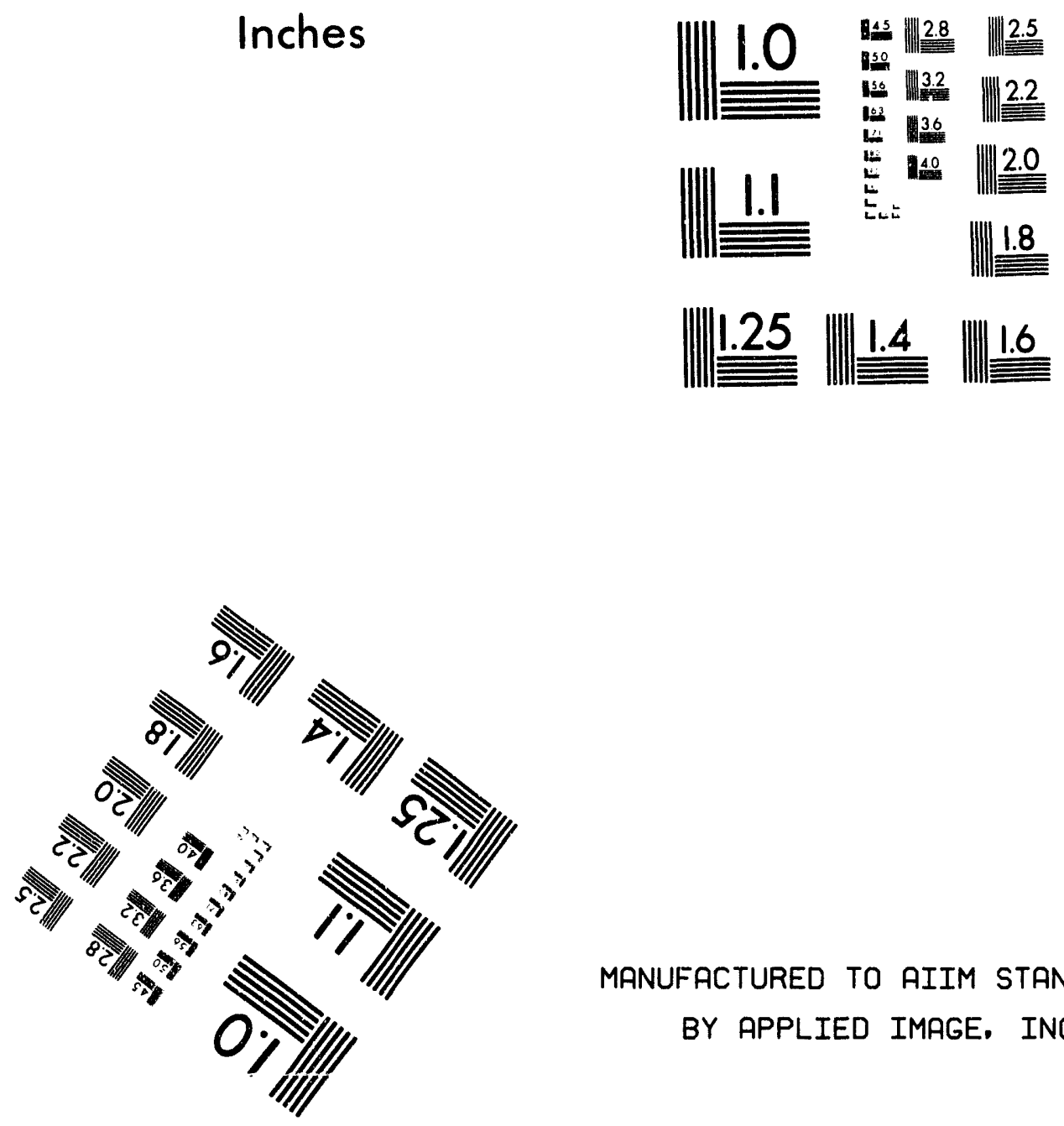

MANUFACTURED TO AIIM STANDARDS

BY APPLIED IMAGE, INC.

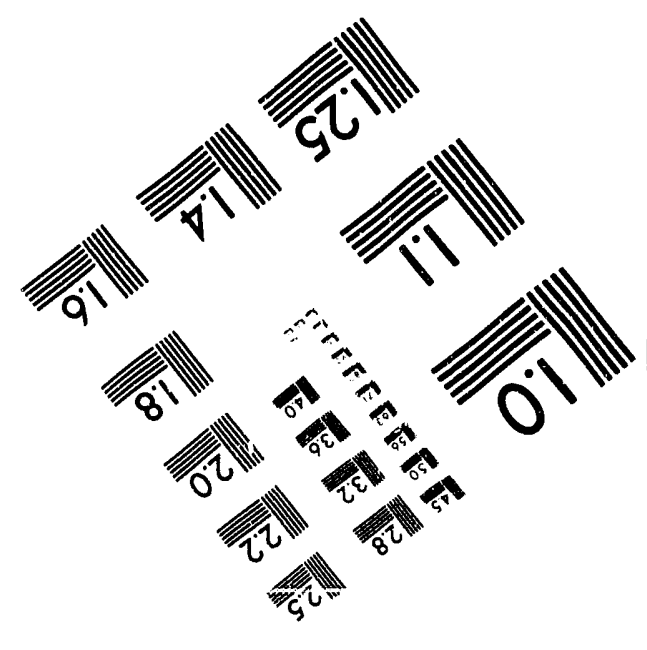



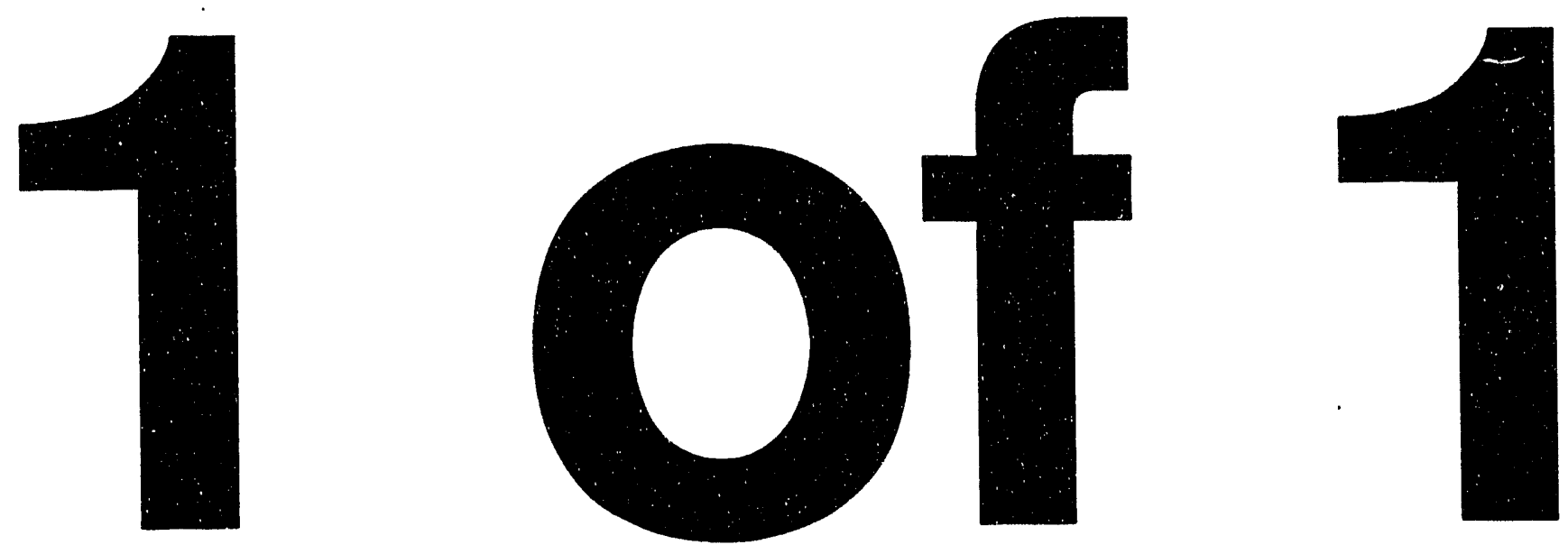


\title{
Ultrafine Aerosol Size Distributions and Sulfuric Acid Vapor Pressures: Implications for new Particle Formation in the Atmosphere
}

\author{
DOE Grant No. DE-FG02-91ER61205
}

\author{
Peter H. McMurry, PI \\ Department of mechanical Engineering \\ University of Minnesota \\ 111 Church St., SE \\ Minneapolis, MN 55455 \\ (612) 625-3345 (Office) \\ (612) 625-6069 (Fax) \\ McMurry@vx.cis.umn.edu (Internet)
}

\section{Year 2 Progress Report}

This project has two components with different but related objectives. One component deals with measurement of $\mathrm{H}_{2} \mathrm{SO}_{4}$ vapor pressures in air under temperature and relative humidity conditions similar to those found in the atmosphere. The second deals with measurement of ultrafine aerosol size distributions. Progress has been made on both tasks during Year 2. However, during Year 2 we have chosen to put more effort into the work on size distribution measurements since this task is progressing very well and is rapidly producing significant results.

\section{Sulfuric acid vapor pressures.}

During Year 1 evaporation rates of $\mathrm{H}_{2} \mathrm{SO}_{4}$ droplets formed by combining hot sulfuric acid vapor with cool air were measured in our laminar flow evaporator. This work was done in part by Mr. Chad Richart as a part of his M.S. thesis research. We found that the apparent $\mathrm{H}_{2} \mathrm{SO}_{4}$ vapor pressures that were inferred from these measurements tended to decrease with time. We postulated that this decrease was either due to the presence of nonvolatile contaminants in the droplets or to the presence of a gas phase contaminant in the reactor such as ammonia $\left(\mathrm{NH}_{3}\right)$. Both of these effects would cause the droplet composition to change during the droplet's residence time in the reactor. This change in composition would affect the $\mathrm{H}_{2} \mathrm{SO}_{4}$ vapor pressure above the droplet surface.

We developed a new technique for producing the sulfuric acid droplets that, we feel should largely eliminate impurities within the droplets as they are formed. This technique involved blending humidified pure air with air that is bubbled through fuming sulfuric acid. Results of measurements with $\mathrm{H} 2 \mathrm{SO} 4$ droplets that were produced in this way are shown in Figure 1. The ordinate shows the experimentally derived vapor pressures from the measured extent of droplet shrinkage and residence time. The abscissa shows the locations in the laminar flow reactor at which the initial and final droplet diameters were measured. For example, "inlet" measurements were made immediately upstream of the evaporator, and "port 1" measurements were made at the first sampling port. Independent measurements were done to determine flow times between these sampling points.

The data in Figure 1 indicate that vapor pressures measured near the inlet to the evaporator have vapor pressures that are close to those reported by Gmitro and Vermeullen (G\&V, 1963) while vapor pressures that were measured further downstream are about a factor of ten smaller $(G \& V / 10)$. As was discussed in our original proposal, the most recent measurements by Roedel (1979), Ayers (1980), and Richardson et al. (1986) are consistent with values that are a factor of ten smaller than Gmitro and Vermeullen's values. Given the difficulty we have encountered in repeating our measurements we do not yet feel that we have a basis for determining the "correct" value from our data. We are inclined to

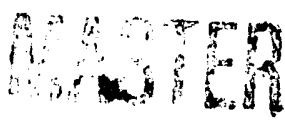


Vapor Pressure of Sulfuric Acid at $35.0 \mathrm{C}$ taken on 06/08/92 Dinitial $=0.1055$ um

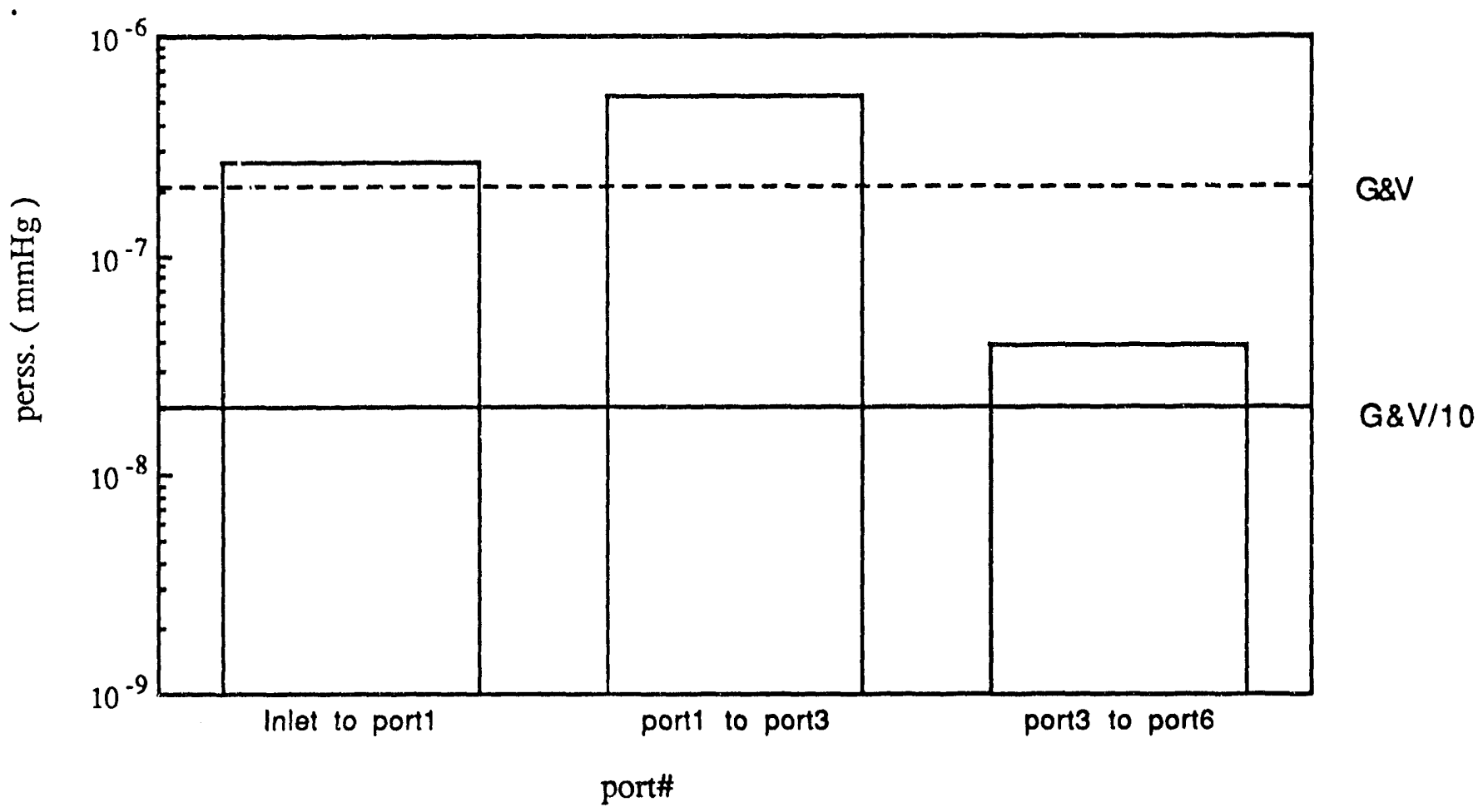

Vapor Pressure of Sulfric Acid at 35.0 C taken on $06 / 08 / 92$ Dinitial $=0.1180$ um

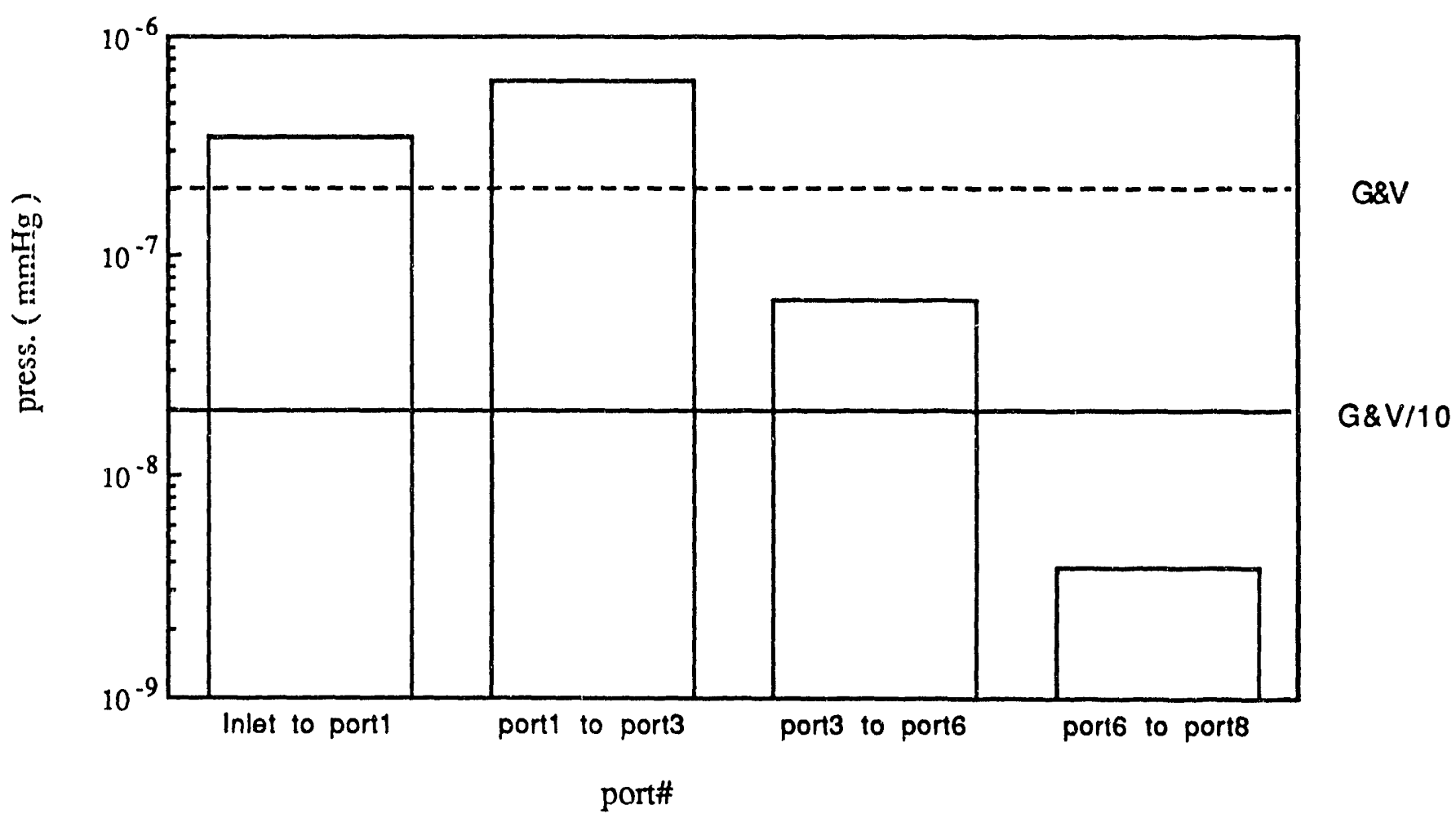

Figure 1. Vapor pressures estimated from measurement of particle shrinkage at various locations in our laminar flow evaporator apparatus. 
feel that measurements that were made near the inlet to the evaporator might be more nearly correct, since these particles would have less time to be affected by contamination. If this is the case, then the correct value could be closer to values reported originally by Gmitro and Vermeullen.

\section{Ultrafine Aerosol Measurements}

Progress that on ultrafine aerosol measurements during Year 2 includes:

1. Participation in Mauna Loa Observatory Photochemistry Experiment intensives (MLOPEX II), Hawaii, during July, 1992.

2. Plans to apply state-of-the-art work on nucleation theory to the analysis of data collected during the measurements in Mauna Loa were developed.

3. Participation in a workshop during September, 1992, for the analysis of data collected during the International Arctic Ocean Expedition 1991. This workshop was held in Stockholm, Sweden. A manuscript that compares four different methods for measuring ultrafine size distributions (two of which were developed with support from this project) was prepared and submitted for review in an archival journal.

4. Plans were made to build an improved instrument for measuring of ultrafine aerosol size distributions in the 3 to $10 \mathrm{~nm}$ diameter range were initiated. We plan to build this instrument during the remainder of Year 2.

Work on these tasks is briefly summarized below.

1. The Mauna Loa measurements were done in collaboration with Dr. Fred Eisele of the Georgia Tech Research Institute. We measured ultrafine size distributions using a specially designed ultrafine condensation nucleus counter that was equipped to make measurements using the pulse height analysis mode (see original proposal or the attached manuscript). This instrument provided information on size distributions in the 3 to $8 \mathrm{~nm}$ diameter range. We also measured particles in the 10 to $500 \mathrm{~nm}$ diameter range with a Scanning Electrical Mobility Spectrometer (SEMS) that we built for the Mauna Loa measurements. Dr. Eisele used mass spectrometric techniques developed in his laboratories to measure $\mathrm{OH}, \mathrm{SO}_{2}, \mathrm{H}_{2} \mathrm{SO}_{4}$, methanesulfonic acid (MSA), and large molecular clusters (5,000 to $10,000 \mathrm{amu})$. Note that the size ranges of clusters measured by Eisele overlapped the ultrafine particle size range measured with our system.

Examples of results from these measurements are shown in Figures 2-4. On July 11 both instruments agree that there is little indication of new particle formation (Figure 2). On July 13, after restarting the mass spectrometer system which has shut off overnight, both large molecular clusters and ultrafine particles were observed from about 9:00 -18:00 hours by both systems (Figure 3). Both systems also showed their disappearance at about sunset. The latter measurements made this past summer (1992) represent the first attempt of Eisele and coworkers to impart a charge to and subsequently measure large atmospheric molecular clusters with a mass spectrometer system. Thus the results of the mass spectrometer technique are still preliminary. Nevertheless, the close correlation of the measurements from these two independent measurements are encouraging.

Data for time-dependent $\mathrm{H}_{2} \mathrm{SO}_{4}$ concentrations (and of gas phase precursors including $\mathrm{SO}_{2}, \mathrm{OH}$, etc.) were also obtained (Figure 4). thus for the first time ever it has been possible to measure species that determine the key gas phase transformation rates, the concentrations of nucleating gas phase species and the entire size spectrum of the condensed phase, ranging from molecular clusters to bulk particles of $500 \mathrm{~nm}$ in diameter. Significantly, this work was conducted on Mauna Loa, which demonstrates the suitability of these techniques to perform at concentration levels found in the background troposphere. 


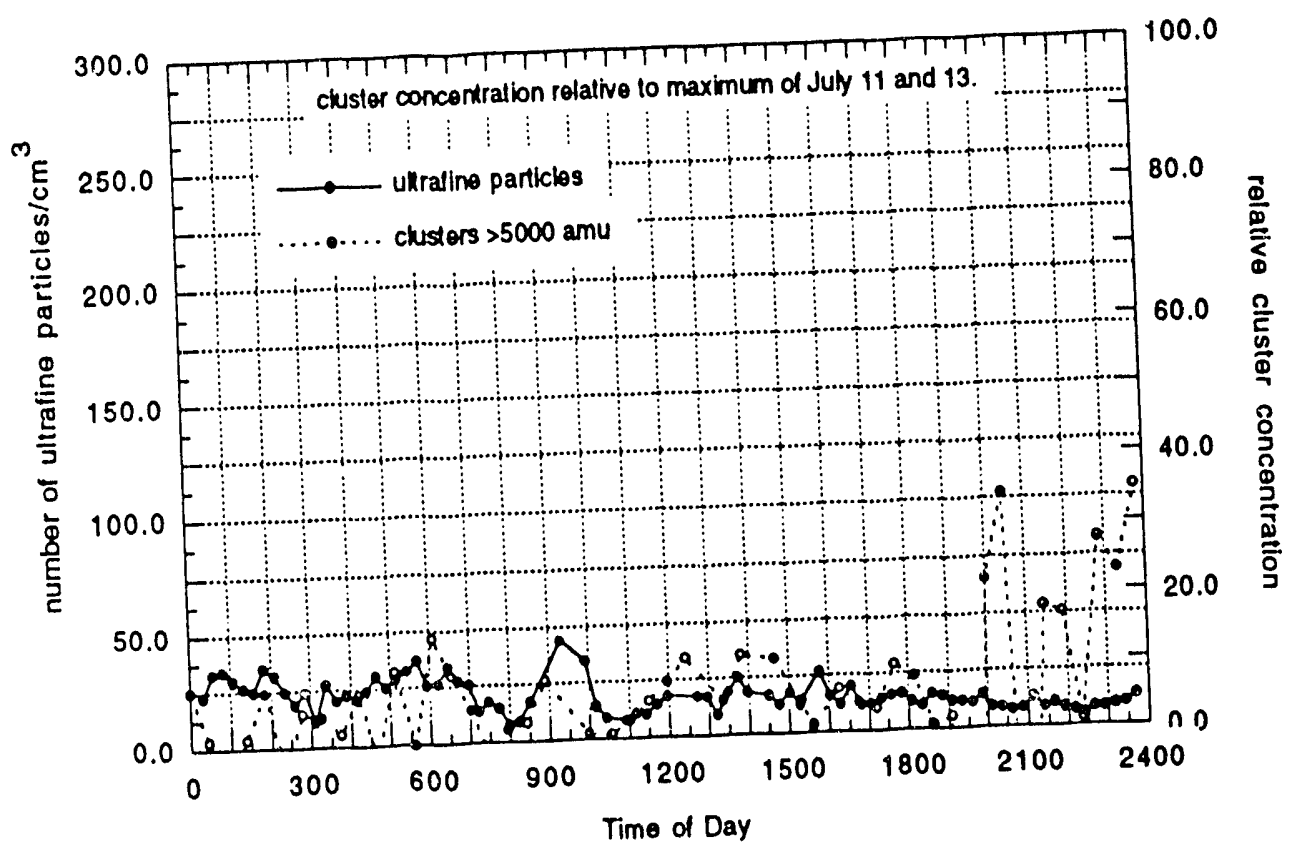

Figure 2. Relative concentration of molecular clusters and concentration of ultrafine particles ( 3 to $8.5 \mathrm{~nm}$ diameter) measured on a day when there was little to no indication of new particle formation. (Mauna Loa Observatory; July 11, 1992).

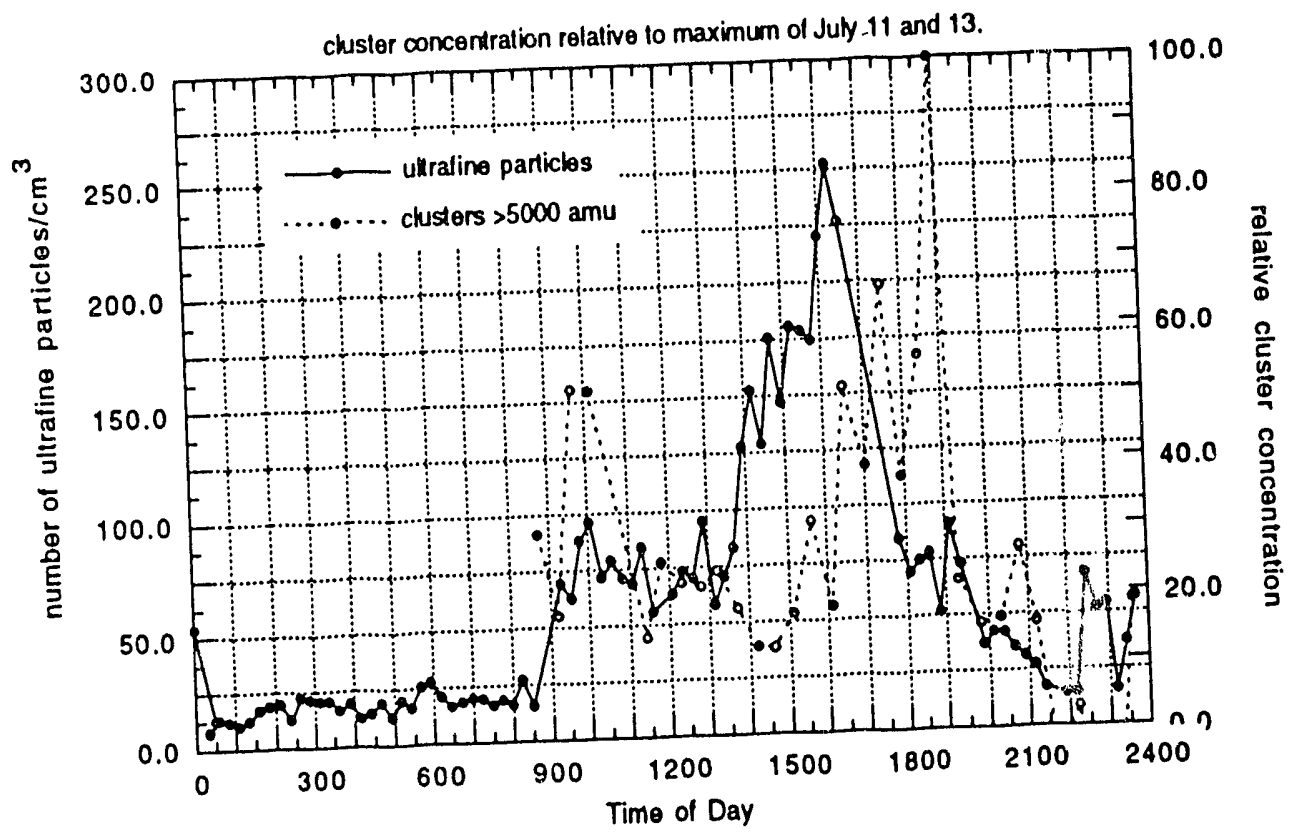

Figure 3. Relative concentration of molecular clusters and concentration of ultrafine particles ( 3 to $8.5 \mathrm{~nm}$ diameter) on a day when there were indications of new particle formation. (Mauna Loa Obsenvatory; July 13, 1992). 


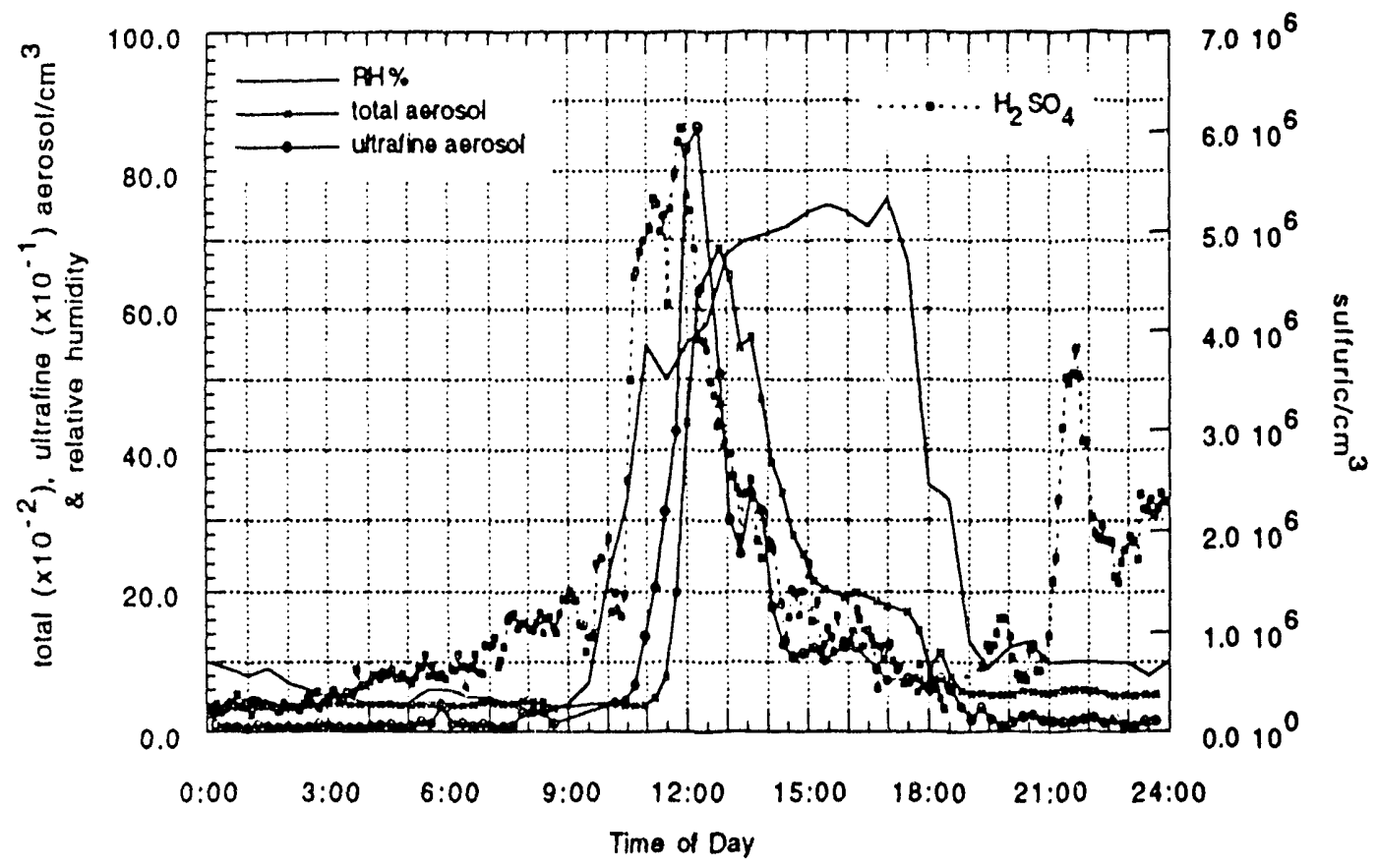

Figure 4. Concentrations of ultrafine particles ( $3108.5 \mathrm{~nm}$ diameter) and total particles in conjunction with gas phase precursors $\mathrm{H}_{2} \mathrm{SO}_{4}$ and $\mathrm{H}_{2} \mathrm{O}$. (Mauna Loa Observatory; July 15,1992 ). 
2. We met with Prof. Sonia Kreidenweis, Colorado State University, on January 22, 1993, to discuss possibilities for applying her work on heteromolecular nucleation in the $\mathrm{H}_{2} \mathrm{O}-\mathrm{H}_{2} \mathrm{SO}_{4}$ - $\mathrm{MSA}$ system to the data collected on Mauna Loa. We have agreed to collaborate on applying of her state-of-the-art moment model technique for the heteromolecular nucleation of sulfuric acid, methanesulfonic acid and water. In addition, we plan to apply our discrete-sectional model for theoretical calculations. Our methods offer the advantage that they provide more detailed information than might be otherwise available. Dr. Kreidenweis' models have the advantage that they include state-of-the-art thermodynamic properties for the nucleating species, and are sufficiently simple to use that they might be candidates for use in comprehensive global climate models.

3. A manuscript that describes the pros and cons of four different techniques for measuring size distributions down to $3 \mathrm{~nm}$ was written during the Stockholm workshop. This manuscript has been submitted for publication in a refereed journal. We also plan to prepare another paper that will attempt to identify atmospheric chemical phenomena that lead to nucleation.

4. We met with representatives of TSI, Inc on October 30, 1992, to discuss our plans for a new instrument for measuring ultrafine particle size distributions. This new instrument will include four independent CNC detectors operating in parallel. Each detector will be operated with a different condenser temperature, such that each detector will have a well-defined minimum detectable particle size (see original proposal which discusses the effect of condenser temperature on minimum detectable particle size). The concentration of particles in a given size range will be determined by difference.

abitract Origy / mimind

\title{
DISCLAIMER
}

\begin{abstract}
This report was prepared as an account of work sponsored by an agency of the United States Government. Neither the United States Government nor any agency thereof, nor any of their employees, makes any warranty, express or implied, or assumes any legal liability or responsibility for the accuracy, completeness, or usefulness of any information, apparatus, product, or process disclosed, or represents that its use would not infringe privately owned rights. Reference herein to any specific commercial product, process, or service by trade name, trademark, manufacturer, or otherwise does not necessarily constitute or imply its endorsement, recommendation, or favoring by the United States Government or any agency thereof. The views and opinions of authors expressed herein do not necessarily state or reflect those of the United States Government or any agency thereof.
\end{abstract}



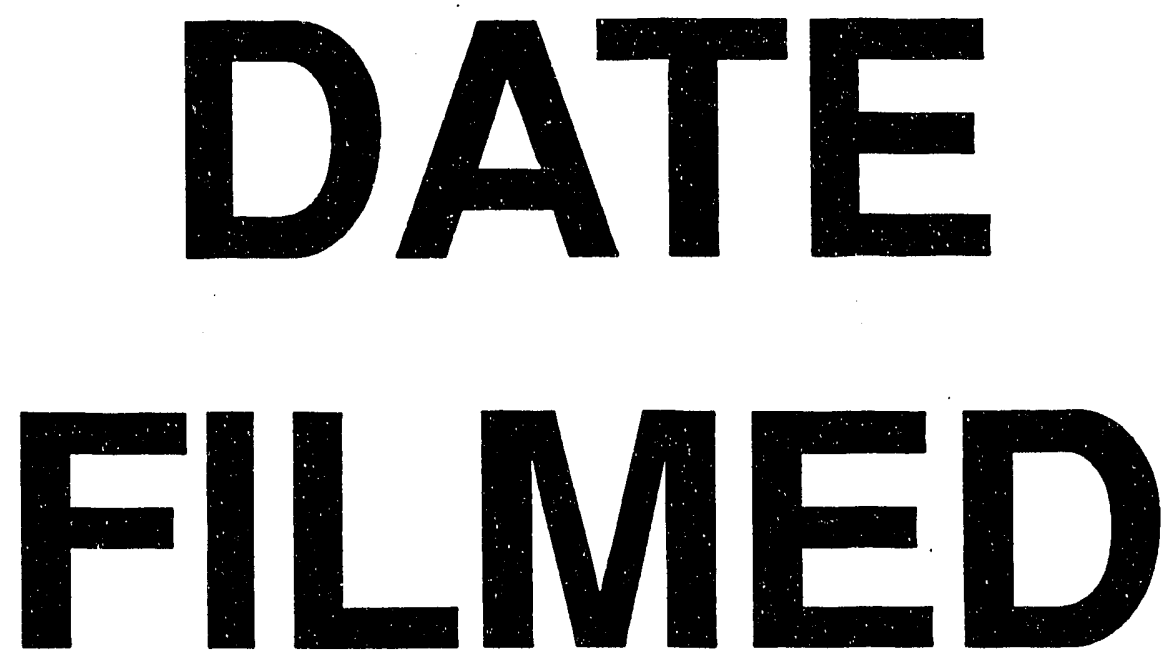

$8 / 18 / 93$
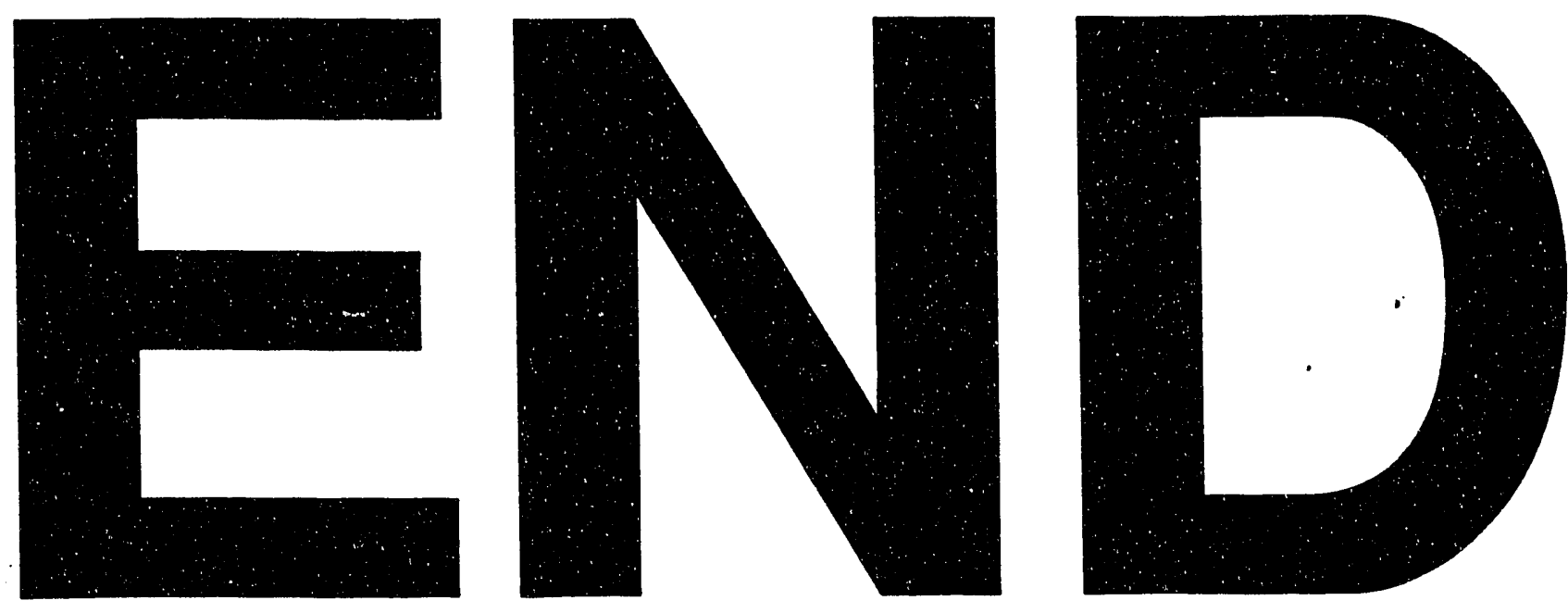
